\title{
Effective Management of Manufacturing Supply Chain Risks: A Sri Lankan Perspective
}

\author{
P.T.R.S. Sugathadasa, H.N. Perera and A.K. Liyanage
}

\begin{abstract}
Due to the increasing vulnerability of supply chains, the concepts of supply chain risk management and supply chain resilience have gained attention both in the industry and in academia, globally. This research focused on the supply chain risk management landscape in Sri Lanka's manufacturing industries as prevalent in mid-2019. To understand this, an investigation on the maturity of supply chain risk management processes in Sri Lankan organisations was carried out during the month of June in 2019. The research further extended to explore the practitioner perception on supply chain vulnerability and to examine the relationships among supply chain vulnerability, supply chain risk management maturity, and supply chain resilience for the Sri Lankan manufacturing sector. To gather data for the research, a carefully designed online questionnaire was circulated among industry practitioners in Sri Lanka representing the management tier of their employer. Altogether 42 responses were received of which 39 were considered for analysis that comprised a confirmatory factor analysis to validate the adopted theoretical model. The findings suggest that overall supply chain risk management process maturity in Sri Lanka is at a 'proactive' level where individual firms have succeeded in adopting formal standalone processes to counteract supply chain risks despite failing to achieve significant integration across the end-to-end supply chain. It could also be concluded that Sri Lankan supply chain professionals perceive vulnerability of Sri Lankan supply chains as being moderate and that supply chain risk management process maturity positively influences supply chain resilience in the Sri Lankan context.
\end{abstract}

Keywords: Supply chain resilience, Supply chain risk management, Supply chain risk management process maturity, Supply chain vulnerability

\section{Introduction}

A supply chain can be viewed as a network of organisations involved in moving a product or a service, together with related information and cash flows, between an origin and a destination. Due to this interconnected nature of organisations in a supply chain, supply chains are exposed not only to vulnerabilities of individual organisations but also to the vulnerabilities created by organisational interconnections as well as the external environments in which the supply chains operate [1]. These environmental, network related and organisational vulnerabilities act as inherent risk sources for a supply chain [2],[3]. In addition to the above inherent risk sources, in recent years, supply chains have become more susceptible to disturbances by adoption of contemporary supply chain strategies such as global sourcing, outsourcing, lean manufacturing, Just-In-Time inventory management, high customisation of products, short product life cycles, etc. [4-6]. Despite these supply chain strategies increasing the vulnerabilities of supply chains, they have proved immensely important in increasing the competitiveness of supply chains in terms of cost efficiency and customer satisfaction. As such, reversing these strategies is not a viable option for any supply chain aiming to remain competitive in this highly demanding environment. Rather, as a potential solution for aforesaid vulnerabilities of supply chains, both the industry and academia have turned their attention to areas of supply chain risk management and supply chain resilience [2],[7],[8].

Eng. (Dr.) P.T.R.S. Sugathadasa, CEng, PMP, MIE(SL), B.Sc.Eng(Hons) (Moratuwa), MSc.Eng (Moratuwa), MBA (Colombo), PhD (Moratuwa), Senior Lecturer, Department of Transport and Logistics Management, University of Moratuwa.

Email:ranilsugathadasa@gmail.com

(10) http://orcid.org/0000-0002-2841-8332

Dr. H.N.Perera, B.Sc.TLM(Hons) (Moratuwa), GradCert (AIB), PhD (Sydney), MIEEE Senior Lecturer, Department of Transport and Logistics Management, University of Moratuwa.

Email:hniles@uom.lk

(ii) http://orcid.org/0000-0001-6329-5967

Mr. A.K. Liyanage, B.Sc.(Hons) (Colombo), PGDip (Palmerston North), MBA (Moratuwa), Supply Chain Practitioner

Email:athalanka@gmail.com

(iD http://orcid.org/0000-0001-7945-2293 
Despite the increased attention globally, there has been little effort in conducting empirical research on supply chain risk management and supply chain resilience in the Sri Lankan context. Even the few attempts that have been made in this regard have either focused on a specific application or have been conducted in isolation, either on supply chain risk management or supply chain resilience [9-11]. This research attempts to adopt a broader view into supply chain risk management landscape in Sri Lanka by ( $a$ ) understanding the maturity of supply chain risk management processes among organisations in manufacturing supply chains in Sri Lanka; (b) exploring the perception on supply chain vulnerability among Sri Lankan supply chain management professionals within manufacturing supply chains; and (c) understanding the relationships among supply chain vulnerability, supply chain risk management process maturity and supply chain resilience, with respect to Sri Lankan manufacturing supply chains.

\section{Literature Review}

\subsection{Supply Chain Risks, Risk Drivers and Risk Sources}

Any unwanted negative deviation from the expected supply chain outcome, that can adversely affect supply chain operations and may result in detrimental consequences to focal firm, could be defined as a supply chain risk [1], [12], [13].

Various attempts have been made in the literature to identify drivers behind supply chain risks [4], [7], [14-16]. In one such attempt, nine drivers, namely random phenomena, competition, accidents, economy, governments and politics, social discontent, non-compliance, international disruptions, and supplier failure, have been identified as the main drivers of supply chain risks [7]. In another attempt, contemporary supply chain features, such as increased competition among supply chains, complex product offerings to satisfy a range of customers, lengthy and complex supply chains due to globalisation, lean supply chain practices, increasing trends towards outsourcing and single sourcing, have been identified as reasons driving supply chain risks in recent years [4].

On top of these attempts, to understand supply chain risk drivers, further efforts have been made to classify these supply chain risk drivers into common sources [1], [3], [4], [15]. In one such classification, three supply chain risk sources, namely environmental risk sources, network related risk sources and organisational risk sources, have been identified [1]. This classification, despite capturing the complexities of supply chain operational interdependencies among organisations and environments, remains simple to understand and execute. Figure 1 below supports the visualisation of the same.

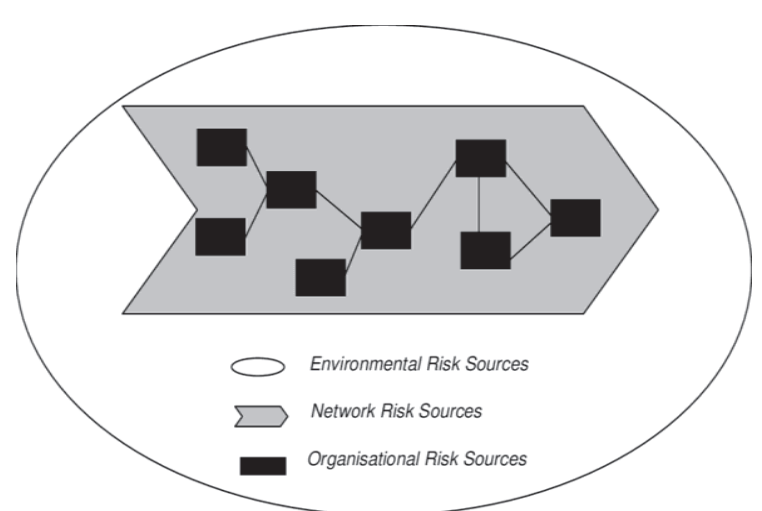

Figure 1 - Risk Sources in Supply Chain [1]

Environmental risk sources are concerned with any uncertainties arising from interaction between supply chain and environment, such as socio-political actions and acts of god. Organisational risk sources are concerned with intra-organisational uncertainties such as strikes, machine failures and IT system malfunctioning, etc. Network related risk sources are concerned with risks and risk drivers arising due to inter-organisational interactions within a supply chain. These may include lack of ownership, chaos, and inertia, etc.

\subsection{Supply Chain Risk Management}

Risk management in general can be understood as a methodological approach to managing uncertainty outcomes. Many authors, including the International Standards Organisation (ISO), have attempted to define risk management and to introduce risk management tools/approaches. Figure 2 below presents the risk management process introduced in ISO 31000 .

As can be seen from Figure 2, establishing scope, context and criteria acts as the overall backdrop against which the whole process will unfold. Risk identification aims to generate a comprehensive list of risks from different sources. Risk analysis attempts to establish negative consequences and probability of occurrence related to risks identified in risk identification step. 


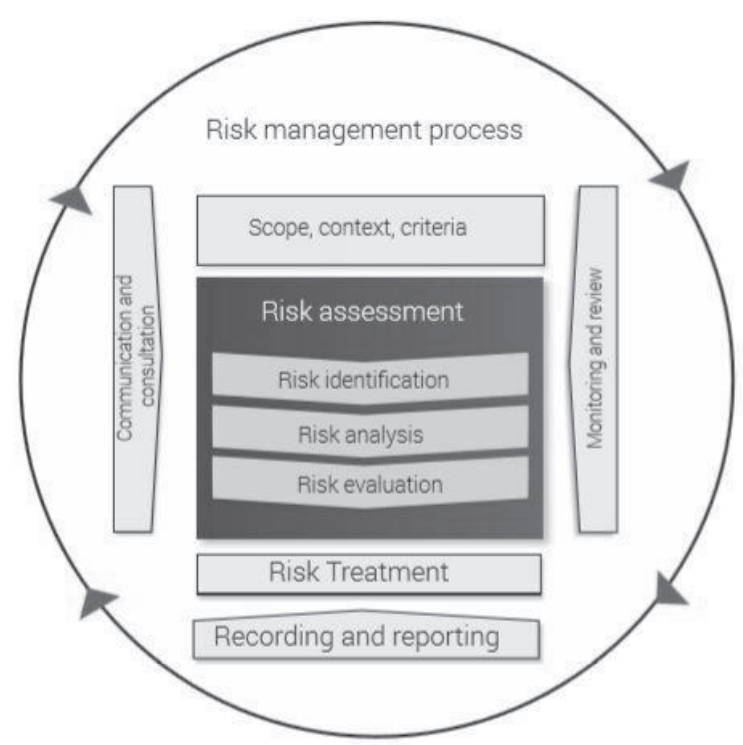

Figure 2 - Risk Management Process [17]

Risk evaluation is concerned with establishing treatment priorities for each of the risks based on the analysis done in the previous step. Risk identification, analysis and evaluation put together are known as the risk assessment stage of the risk management process. Risk treatment step in ISO 3100 risk management process shown in Figure 2 is concerned with establishing potential options to deal with risks. These potential options could include avoidance, acceptance, alteration, sharing or retaining strategies. Monitoring \& review, recording \& reporting, and communication \& consultation activities shown in Figure 2 above are present to enhance the process to improve the outcome. In addition to the above risk management process, a risk management framework inclusive of six aspects, namely leadership and commitment, design, implementation, evaluation, improvement, and integration, has also been outlined in ISO 31000. This risk management framework would ultimately determine the overall effectiveness and efficiency of an organisation's risk management efforts.

The above mentioned academic and practitioner work on general risk management led us to find a sizable literature cluster that focuses on supply chain risk management (SCRM) [2], [3], [18-21]. Drawing from this cluster of literature, SCRM in general could be understood as the process by which any risk to information, material, and product flows from supplier to end-user is managed [2]. In a more specific definition of SCRM, it has been defined as "the identification and management of risks for the supply chain, through a co-ordinated approach among supply chain members, to reduce supply chain vulnerability as a whole" (p.206 [1]). Considering the above definition, processes/activities involved in SCRM are identical to those of general risk management, but the differentiation is in the scope in which they are practiced. SCRM specifically focuses on supply chain related risks concerning the whole supply chain and, as such, management efforts extend beyond organisational boundaries to collaborate with all supply chain members. Concurrently, general risk management considers a wider range of risks such as financial, market, etc., but its coverage is mostly confined within organisational boundaries. With this view, it could be concluded that the SCRM process can be harmonised with the ISO 31000 standard for general risk management [17]. Therefore, for the purpose of this study, SCRM process was considered in conjunction with the risk management process detailed in ISO 31000 with specific focus on supply chain related risks and covering an end-to-end supply chain scope.

\subsection{Supply Chain Risk Management Maturity Model}

Maturity models are commonplace in academic literature on a variety of disciplines, including supply chain management [22-25]. Accordingly, some publications were found on SCRM maturity models. In one of those studies, an attempt has been made to evaluate SCRM maturity by referring to the level of integration of the activities in the Supply Chain Operations Reference (SCOR) Model along the supply chain [26]. In another effort, SCRM maturity has been attempted to be measured by evaluating four factors, namely organisation, technicality, transparency, and involvement 
[27]. Despite these works, the available knowledge on SCRM maturity models in the academic literature remains largely limited and, to fill this knowledge gap, a few practitioner groups/consultancies have also put forward their own maturity models on SCRM. One such practitioner model put forward by Supply Chain Risk Leadership Council (SCRLC), a cross industry council working to create and promote best practices in SCRM, attempts to establish the maturity level an organisation has achieved in managing its supply chain risks by assessing the depth and breadth of SCRM Leadership, SCRM Planning, SCRM Implementation, SCRM Evaluation and SCRM Improvement aspects. To assess how well above attributes are practised within the organisation, SCRLC proposes to measure the depth and the breadth of 23 activities/subprocesses. Table 1 illustrates how these 23 activities/sub-processes are connected to each of the five main attributes. SCRLC SCRM maturity model was in harmony with ISO 31000 standard for general risk management [17] and it encapsulated observed academic literature [26-28] all the while providing unambiguous guidelines to measure the SCRM maturity of an organisation. Given this, for the purpose of this study, SCRM maturity model introduced by SCRLC was adopted in measuring SCRM maturities of organisations in manufacturing supply chains in Sri Lanka.

There are five maturity levels defined for each of the twenty-three activities/sub-processes in SCRLC SCRM maturity model. The level of maturity is determined depending on the formality in which each of the twenty-three activities/sub-processes is being practised and the level of integration along the supply chain for the same. Each of these maturity levels is well defined in the grid format so that there is little room for ambiguity. Depending on the maturity for individual activities/subprocesses, the overall maturity for the SCRM process in concern will be derived as Reactive, Aware, Proactive, Integrated or Resilient, where 'Reactive' level is the least mature stage and 'Resilient' level is the fully mature stage. Figure 3 attempts to illustrate the composition of the SCRLC'S SCRM process maturity grid in a schematic format.

\subsection{Supply Chain Resilience}

In terms of enterprise resilience, resilience can be defined as "the ability to bounce back from a disruption" (p.41 [30]). Extending from this definition of enterprise resilience, supply chain resilience can be defined as "the adaptive capability of a supply chain to reduce the probability of facing sudden disturbances, resist the spread of disturbances by maintaining control over structures and functions, and recover and respond by immediate and effective reactive plans to transcend the disturbances and to restore the supply chain to a robust state of operation" (p. 121 [31]). As can be seen from above definition, supply chain resilience is not purely a reactive strategy, but it also has an element of proactiveness attached to it. Therefore, in simple terms, supply chain resilience can be viewed as the quality of a supply chain to be prepared for an unexpected event, to resist and to respond efficiently should an event materialise, and to recover from it to ensure sustainable competitive advantage. This definition of supply chain resilience is presented in Figure 4.

Table 1 - Mapping of Activities/ SubProcesses to Main Attributes in SCRLC Maturity Model [29]

\begin{tabular}{|c|c|}
\hline Main Attribute & Activity/ Sub-process \\
\hline \multirow{5}{*}{$\begin{array}{l}\text { SCRM } \\
\text { Leadership }\end{array}$} & Executive Leadership \\
\hline & Governance \\
\hline & Functional Leadership \\
\hline & Resources \& Commitment \\
\hline & Programme Communication \\
\hline \multirow{10}{*}{ SCRM Planning } & Supply Chain Mapping \\
\hline & $\begin{array}{l}\text { Context \& Operational } \\
\text { Environment }\end{array}$ \\
\hline & Stakeholder Identification \\
\hline & Risk Tolerance Identification \\
\hline & Risk Category Identification \\
\hline & Business Impact Identification \\
\hline & Event Likelihood \& Consequence \\
\hline & Risk Prioritisation \\
\hline & Risk Treatment Identification \\
\hline & Stakeholder Consultation \\
\hline \multirow{3}{*}{$\begin{array}{l}\text { SCRM } \\
\text { Implementation }\end{array}$} & Risk Monitoring \\
\hline & Risk Treatment Execution \\
\hline & Event Communication \\
\hline \multirow{3}{*}{ SCRM Evaluation } & Programme Metrix \\
\hline & Performance Review \\
\hline & Audit / Drill / Test \\
\hline \multirow{2}{*}{$\begin{array}{l}\text { SCRM } \\
\text { Improvement }\end{array}$} & Continuous Improvement \\
\hline & Change Management \\
\hline
\end{tabular}


Increasing formality of SCRM activities/ sub-processes

Increasing intergration with supply chain partners

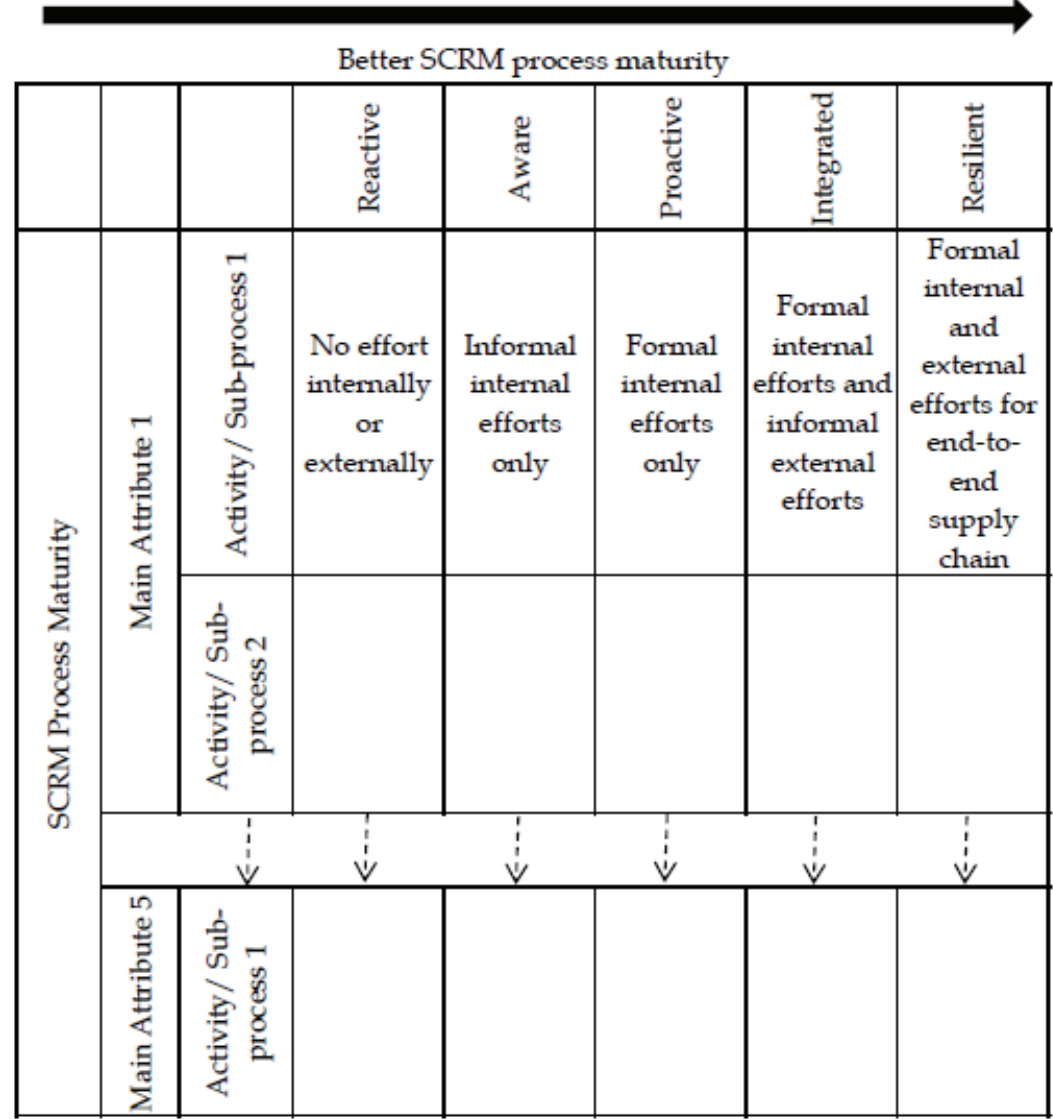

Figure 3 - Composition of SCRLC SCRM Process Maturity Grid

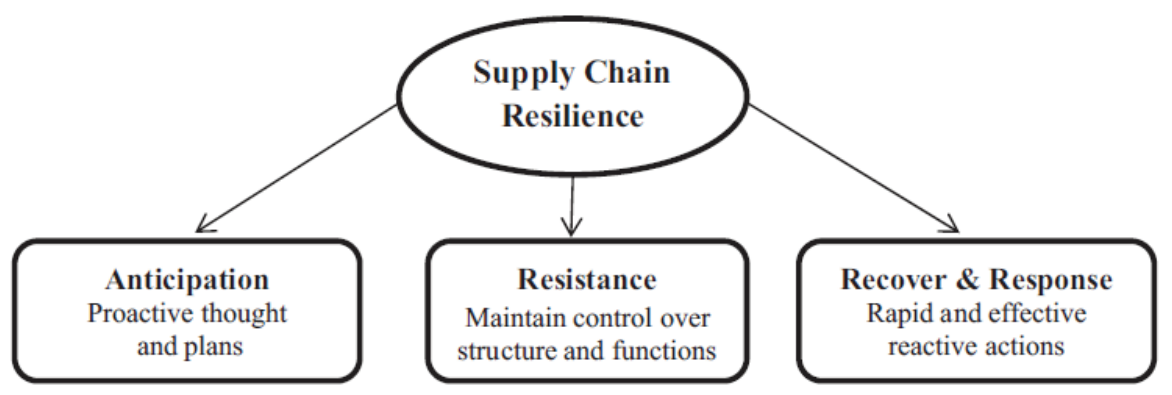

Figure 4 - Supply Chain Resilience [31]

\section{Methodology}

\subsection{Conceptual Model}

Setting up the underlying theoretical framework for the research included determining measurement variables and establishing a set of hypotheses to answer the research questions identified. To understand SCRM process maturity among Sri Lankan organisations, SCRLC's SCRM maturity model described in Section 2.3 was adopted. Accordingly, it was decided to treat 23 activities/sub-processes in SCRLC SCRM maturity model as measurement variables for
SCRM process maturity under this research. Following the SCRLC SCRM maturity model, these 23 measured variables converged on 5 first order latent variables, namely Leadership, Planning, Implementation, Evaluation and Improvement, before they were converged on the second order latent variable of SCRM Maturity. To explore the perception on supply chain vulnerability among Sri Lankan supply chain management professionals, supply chain risk sources classification put forward by Juttner et al. [1] was adopted under this research. Accordingly, susceptibility of a particular supply chain to organisational uncertainties, network uncertainties and 
environmental uncertainties were attempted to be measured to assess its overall vulnerability. For the purpose of evaluating supply chain resilience to understand its relationship with supply chain vulnerability and SCRM maturity, definition of supply chain resilience as presented in Figure 4 under Section 2.4 was adopted. Accordingly, anticipation, resistance, and recover \& response capabilities of a supply chain were attempted to be measured to assess the overall supply chain resilience. Above mentioned measurement variables, their analysis labels and respective first order latent variables are summarised in Table 2.

Hypothesis development to understand the relationships among supply chain vulnerability, supply chain risk management process maturity and supply chain resilience was fundamentally an extension of the literature review conducted. It was clear from the reviewed literature that increased attention to SCRM was due to increased vulnerability of supply chains [1],[4],[13],[32]. By extension of this understanding, it could be argued that the level of vulnerability of supply chains could influence the maturity of SCRM processes in respective supply chains. Based on this argument the first hypothesis was developed as below.

\section{H1: Supply chain vulnerability positively influences SCRM process maturity.}

The SCRM maturity model studied in the literature review was indicative of that, more mature the SCRM process more resilient the supply chain turned out to be [29]. Similar sentiment was to be found among other reviewed literature as well [14]. In line of this thinking, another hypothesis was developed as stated below.

\section{H2: SCRM process maturity positively} influences supply chain resilience.

After having established above two hypotheses it was intuitive to argue that there could be a relationship between supply chain vulnerability and supply chain resilience as well. Therefore, a third hypothesis was developed.

\section{H3: Supply chain vulnerability positively influences supply chain resilience.}

The overall conceptual model developed for this research is illustrated in Figure 5.
Table 2 - Measured Variables and Latent Variables of the Research

\begin{tabular}{|c|c|c|}
\hline Measured Variable & Label & $\begin{array}{c}\text { 1st Order } \\
\text { Latent Variable }\end{array}$ \\
\hline $\begin{array}{l}\text { Organisational } \\
\text { Uncertainties }\end{array}$ & VULN1 & \multirow{3}{*}{$\begin{array}{l}\text { Supply Chain } \\
\text { Vulnerability }\end{array}$} \\
\hline $\begin{array}{l}\text { Network } \\
\text { Uncertainties }\end{array}$ & VULN2 & \\
\hline $\begin{array}{l}\text { Environmental } \\
\text { Uncertainties }\end{array}$ & VULN3 & \\
\hline $\begin{array}{l}\text { Executive } \\
\text { Leadership }\end{array}$ & LEAD1 & \multirow{5}{*}{ Leadership } \\
\hline Governance & LEAD2 & \\
\hline $\begin{array}{l}\text { Functional } \\
\text { Leadership }\end{array}$ & LEAD3 & \\
\hline $\begin{array}{l}\text { Resources \& } \\
\text { Commitment }\end{array}$ & LEAD4 & \\
\hline $\begin{array}{l}\text { Programme } \\
\text { Communication }\end{array}$ & LEAD5 & \\
\hline $\begin{array}{l}\text { Supply Chain } \\
\text { Mapping }\end{array}$ & PLAN1 & \multirow{10}{*}{ Planning } \\
\hline $\begin{array}{l}\text { Context \& } \\
\text { Operational } \\
\text { Environment }\end{array}$ & PLAN2 & \\
\hline $\begin{array}{l}\text { Stakeholder } \\
\text { Identification }\end{array}$ & PLAN3 & \\
\hline $\begin{array}{l}\text { Risk Tolerance } \\
\text { Identification }\end{array}$ & PLAN4 & \\
\hline $\begin{array}{l}\text { Risk Category } \\
\text { Identification }\end{array}$ & PLAN5 & \\
\hline $\begin{array}{l}\text { Business Impact } \\
\text { Identification }\end{array}$ & PLAN6 & \\
\hline $\begin{array}{l}\text { Event Likelihood \& } \\
\text { Consequences }\end{array}$ & PLAN7 & \\
\hline Risk Prioritisation & PLAN8 & \\
\hline $\begin{array}{l}\text { Risk Treatment } \\
\text { Identification }\end{array}$ & PLAN9 & \\
\hline $\begin{array}{l}\text { Stakeholder } \\
\text { Consultation }\end{array}$ & PLAN10 & \\
\hline Risk Monitoring & IMPL1 & \multirow{3}{*}{ Implementation } \\
\hline $\begin{array}{l}\text { Risk Treatment } \\
\text { Execution }\end{array}$ & IMPL2 & \\
\hline $\begin{array}{l}\text { Event } \\
\text { Communication }\end{array}$ & IMPL3 & \\
\hline Programme Metrix & EVAL1 & \multirow{3}{*}{ Evaluation } \\
\hline Performance Review & EVAL2 & \\
\hline Audit / Drill / Test & EVAL3 & \\
\hline $\begin{array}{l}\text { Continuous } \\
\text { Improvement }\end{array}$ & IMPR1 & \multirow{2}{*}{ Improvement } \\
\hline $\begin{array}{l}\text { Change } \\
\text { Management }\end{array}$ & IMPR2 & \\
\hline Anticipation & RESI1 & \multirow{3}{*}{$\begin{array}{l}\text { Supply Chain } \\
\text { Resilience }\end{array}$} \\
\hline Resistance & RESI2 & \\
\hline Recover \& Response & RESI3 & \\
\hline
\end{tabular}




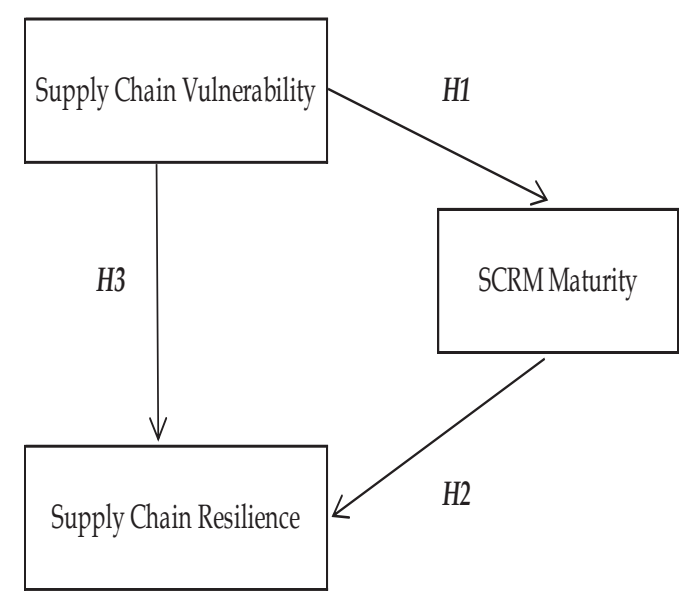

Figure 5 - Conceptual Model of the Research

\subsection{Population, Sample and Data Collection}

For the purpose of this study, the population comprised all individuals who were either directly responsible for the SCRM process or were directly involved in all Sri Lankan organisations that interact with the manufacturing sector. Given the sheer scale of the population, targeting all of them for data collection was certainly not a viable option. Therefore, the need for sampling was apparent. Further, it was difficult to identify exact individuals at each organisation who were directly responsible for/involved in SCRM process. A reason for this was because there were no professionals in any of the organisations approached, whose sole responsibility lay with SCRM. Given these complications, it was decided to select a set of supply chain professionals representing a cross section of industries together with acceptable levels of education and industry experience as the sample for gathering data related to SCRM. Managerial level professionals interacting with manufacturing supply chains were decided as the target group. It was ensured that the respondents had a minimum of seven years experience in the sector. Therefore, the selected candidates could be assumed to bear a clear understanding of the SCRM process even if they were not directly involved in the process. Accordingly, 60 individuals were targeted as the primary sample for data gathering for this research. However, given that the rate of response to this type of studies is never $100 \%$, targeting only those 60 individuals posed a threat in getting an adequate number of responses to conduct a valid analysis. Therefore, an attempt was made to get through to a secondary sample by getting the primary sample to introduce suitable individuals for the study using snowball sampling method. The acceptance of submissions from the secondary sample was conditioned to cleansing by considering the respondents' functional experience in supply chain management as stated above.

Considering the profiles of the respondents and given the time constraints, it was decided to use a structured online questionnaire as the primary data collection tool for this research. Questionnaires are regarded as an efficient and effective tool for data gathering, particularly in studies where there is clarity on the variables to be measured [33]. Given that the theoretical framework of this research provided a clear understanding as to what needs to be measured and how it would be done, administering an online questionnaire was a valid and acceptable approach for data gathering for this research. The questionnaire was circulated among the members of the primary sample during the first week of June 2019 and it was followed up with three weekly reminders. Responses received by the end of June 2019 were considered for analysis stage.

\subsection{Data Analysis}

A descriptive analysis and a correlation analysis would have sufficed to provide answers to identified research questions and to test the established hypothesis. However, prior to moving into these primary analysis methods it was essential to carry out some preliminary analysis on the collected data to establish the reliability and the validity of the primary results. Therefore, initially Kaiser-Meyer-Olkin (KMO) index and the value of Bartlett's Test of Sphericity were calculated to ensure the sample adequacy. This was then followed up by a confirmatory factor analysis (CFA) on the established theoretical framework for the study. Despite the fact that this framework was based on a comprehensive literature review, conducting the CFA to establish convergent validity was still necessary as it had not been applied to the Sri Lankan context previously. In order to validate the reliability of the study, Cronbach's Alpha coefficient was calculated. IBM SPSS and SPSS AMOS were the main software tools employed for all above analyses.

\section{Research Findings}

\subsection{Data Screening and Sample Demographics}

In response to the questionnaire sent out in the beginning of June 2019, a total of 42 responses were received by the end of the same month. 
Out of those responses, three received from the secondary sample had to be omitted from analysis as they did not meet prerequisites in terms of either employment function or employment hierarchy. As such, only 39 responses were considered for the analysis. $72 \%$ of the responses considered for analysis were from the targeted primary sample. Logistics/ Transportation sector was the single most represented industry in the responses with strong representations from Food, Beverage \& Tobacco, Textile, Chemical/Pharmaceutical and Retail industries. Some of the organisations represented under Food, Beverage \& Tobacco and Textile industry verticals were engaged in not only manufacturing and selling of finished goods but were also acting as tier 1 suppliers for other manufacturers in the same industries. Organisations represented under Logistics/ Transportation sector were significant contributors to manufacturing supply chains as they were the major facilitators for the forward and reverse product flows along the manufacturing supply chains. Retail sector organisations were acting as the end customer interface for manufacturing supply chains by making the manufactured goods available for intended end users. Considering all this, it could be safely deduced that an acceptable cross section of Sri Lankan manufacturing supply chain was represented in the responses received. Absolute number of responses received according to respective industries are summarised in Table 3.

Table 3 - Industry-Wise Respondent Split

\begin{tabular}{|l|c|}
\hline \multicolumn{1}{|c|}{ Industry } & Respondents \\
\hline Logistics/ Transportation & 12 \\
\hline Beverage, Food and Tobacco & 7 \\
\hline Textile & 6 \\
\hline $\begin{array}{l}\text { Chemical and } \\
\text { Pharmaceuticals }\end{array}$ & 5 \\
\hline Other & 4 \\
\hline Retail & 4 \\
\hline General Manufacturing & 1 \\
\hline
\end{tabular}

A clear majority of the respondents, representing a $74 \%$ of the total responses, were from Supply Chain/Operations functions of their respective organisations while more than half the total respondents were from Senior/Middle Management positions.

\subsection{Validity and Reliability Analysis}

Both KMO index and the Bartlett's Test of Sphericity returned significant results, indicating adequate sample size for factor analysis. These results are presented in Table 4.

Initial CFA conducted for SCRM Maturity model with all 23 measured variables and 5 first order latent variables resulted in less than 0.7 loadings for LEAD1, PLAN10 and IMPR2 measured variables. Further, the covariance between first order latent variables 'Evaluation' and 'Improvement' was significantly high at 0.85 . Considering these results, the initial model was modified removing low loading observed variables (LEAD1, PLAN10 and IMPR2) and combining high covariant latent variables (Evaluation' and Improvement). CFA for the modified model resulted in more than 0.7 loadings for all observed and first order latent variables indicating an acceptable convergent validity for the SCRM Maturity model.

\section{Table 4 - Sample Adequacy Measures}

\begin{tabular}{|l|l|r|}
\hline \multicolumn{3}{|c|}{ KMO and Bartlett's Test } \\
\hline $\begin{array}{l}\text { Kaiser-Meyer-Olkin Measure of } \\
\text { Sampling Adequacy. }\end{array}$ & .665 \\
\hline $\begin{array}{l}\text { Bartlett's } \\
\text { Test of } \\
\text { Sphericity }\end{array}$ & Approx. Chi-Square & 1204.202 \\
\cline { 2 - 3 } & df & 406 \\
\hline
\end{tabular}

Cronbach's Alpha calculated for the full research model comprising modified SCRM Maturity model with 20 measured variables and 3 measured variables each for supply chain vulnerability and supply chain resilience, resulted in a value of 0.958 , indicating acceptable level reliability for the findings of the study.

\subsection{Descriptive Analysis}

\subsubsection{SCRM Maturity in Sri Lanka}

According to received responses, overall SCRM process maturity for Sri Lankan context appeared to be at a proactive level. Leadership and Planning attributes had generated highly proactive results, while Evaluation and Improvement attribute generating a less than proactive result. Results for major individual industries represented in the research also followed a similar trend to that of overall country, with Textile industry generating the highest overall result for SCRM process maturity. These results are summarised in Figure 6. 


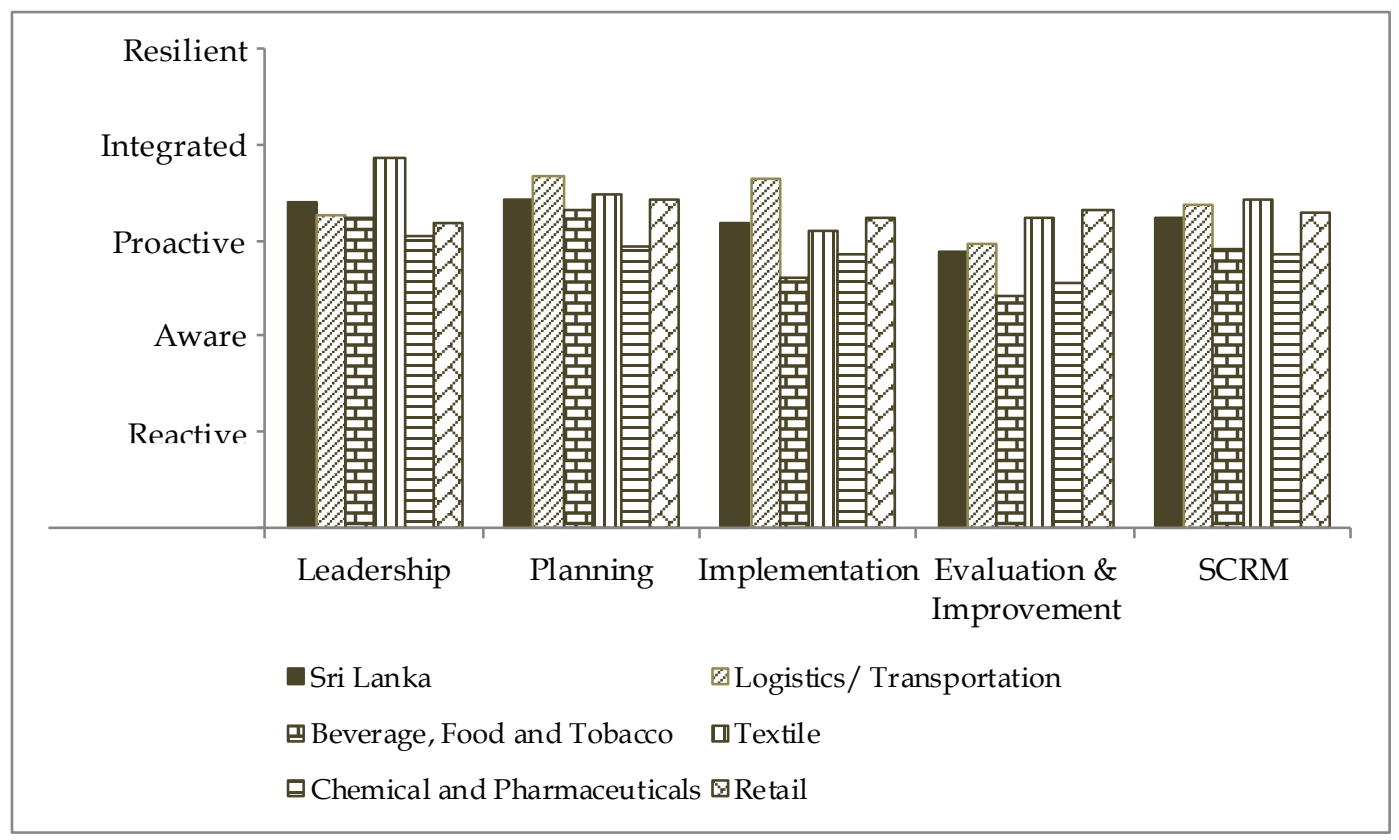

Figure 6 - SCRM Maturity in Sri Lanka

\subsubsection{Supply Chain Vulnerability in Sri Lanka}

In the overall Sri Lankan context, supply chain vulnerability had been recognised as being moderate by the practitioners. Environmental uncertainties had been identified as the most significant individual risk source while Organisational uncertainties had been recognised as the least concerning. In considering major individual industries represented in the research, similar trends to overall Sri Lankan context could be observed with the only exception being Chemical and Pharmaceutical industry which had recognised Network uncertainties to be more pressing than Environmental uncertainties. Highest vulnerability result for an individual industry had been generated by Beverage, Food and Tobacco industry. These results are summarised in Figure 7.

\subsubsection{Supply Chain Resilience in Sri Lanka}

As per responses received, overall supply chain resilience in the Sri Lankan context appeared to be at a moderate level. Recovery \& Response aspect of resilience had been recognised to be the weakest, while Anticipation and Resistance aspects had been recognised considerably stronger to the former. Considering individual industries, Beverage, Food and Tobacco industry had generated stronger results for supply chain resilience over the others while Chemical and Pharmaceutical industry had resulted the weakest overall result. These results are summarised in Figure 8.

\subsection{Regression Analysis}

Table 5 summarises the regression coefficients for relationships among supply chain vulnerability, SCRM maturity and supply chain resilience, in the Sri Lankan context. As can be observed with the values in the table, the regression estimates obtained for relationships between supply chain vulnerability \& SCRM maturity, and between supply chain vulnerability \& supply chain resilience, were suggestive of weak correlations for those relationships. However, the obtained correlation coefficient $(\rho)$ for the relationship between SCRM maturity and supply chain resilience was nearly 0.8 , indicating a strong positive correlation. Obtained coefficient of determination $\left(R^{2}\right)$ for the same relationship was nearly 0.5 indicating that nearly $50 \%$ of the variations in supply chain resilience could be explained by the variations in SCRM maturity. Therefore, only the relationship between SCRM maturity and supply chain resilience could be considered to be displaying a strong positive relationship.

Table 5 - Regression Estimates for SC Vulnerability, SCRM Maturity and SC Resilience

\begin{tabular}{|c|c|c|c|c|}
\hline & \multicolumn{2}{|c|}{ Estimates } \\
\hline & & & $\rho$ & $R^{2}$ \\
\hline Vulnerability & $<>$ & $\begin{array}{c}\text { SCRM } \\
\text { Maturity }\end{array}$ & 0.467 & 0.150 \\
\hline $\begin{array}{c}\text { SCRM } \\
\text { Maturity }\end{array}$ & $<>$ & Resilience & 0.763 & 0.448 \\
\hline Vulnerability & $<>$ & Resilience & 0.478 & 0.137 \\
\hline
\end{tabular}




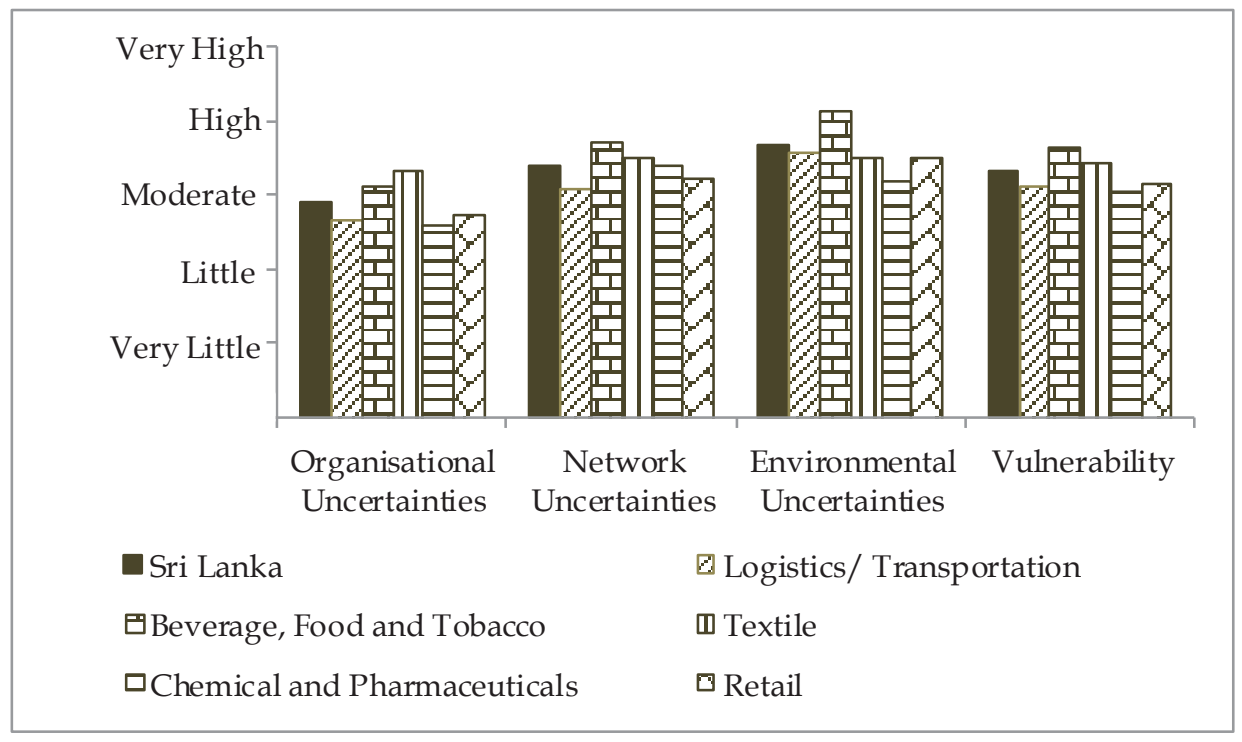

Figure 7 - Supply Chain Vulnerability in Sri Lanka

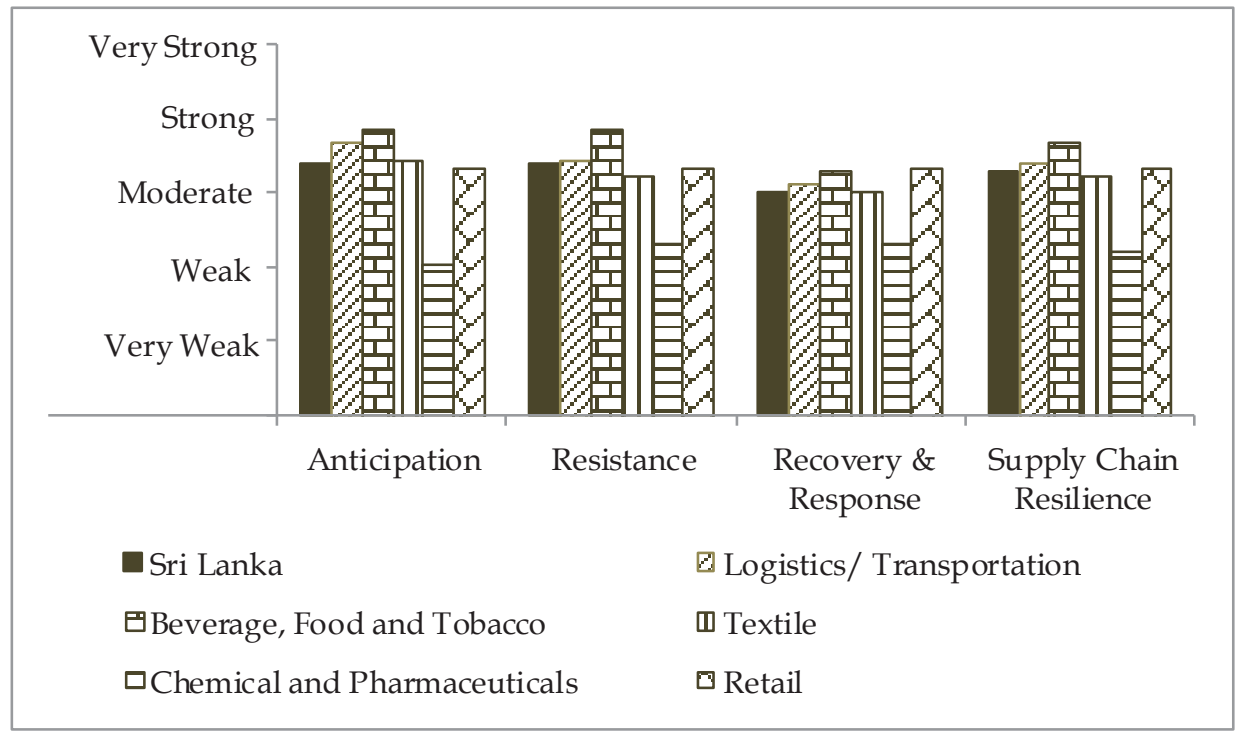

Figure 8 - Supply Chain Resilience in Sri Lanka

\section{Discussion and Conclusion}

SCRM maturity in Sri Lanka appeared to be at 'Proactive' maturity level according to the SCRLC model of SCRM process maturity. No significant variations among industry-wise results were observed herein. Therefore, this result provides evidence to significant, formal, yet internally focused initiatives, on SCRM undertaken by Sri Lankan organisations. In other words, despite individual members in Sri Lankan supply chains taking formal standalone initiatives to SCRM, there has been little success in integrating the end-to-end supply chain by adopting supply chain-wide SCRM initiatives. Therefore, there clearly is a significant opportunity for Sri Lankan supply chains to make improvements into integration of SCRM initiatives. Considering individual attributes in SCRM maturity, Leadership, Planning, and Implementation attributes had displayed proactive level maturity. This can be considered positive evidence to Sri Lanka being more proactive in SCRM as a country. Results for Leadership and Planning attributes were particularly encouraging in this respect.

However, Evaluation \& Improvement attribute had displayed a level of maturity lagging in the overall SCRM maturity, indicating that there needs to be more attention paid to this area of SCRM. This is particularly important considering that any process that has not been 
evaluated and improved on a continuous basis would generate diminishing returns over time. Considering industry-wise SCRM process maturity results, high levels of maturities for Textile manufacturing industry could partly be attributed to the fact that this industry had been predominately represented in this study by a few large and well organised firms. Another possible reason for high level SCRM process maturities for Textile industry could be due to strong SCRM drive of highly powerful and process driven global customers Sri Lankan Textile manufacturing industry caters to. It is possible that these global customers are demanding stronger SCRM focus and initiatives from their suppliers in Sri Lanka and that could in turn drive the maturity of SCRM for the industry to a higher level. Poorer results for SCRM process maturities for the Beverage, Food and Tobacco industry could partly be attributed to the fact that the industry had been represented by a mix of firms with varying scales of operations. Relatively large standard deviations for each of the SCRM attributes could be considered evidence to support this hypothesis. However, it still was a surprising result given there was a sizeable representation from large multinational players who supposedly should adopt more mature SCRM processes.

Sri Lankan supply chain practitioners appeared to perceive overall supply chain vulnerability in Sri Lanka as being moderate. Industry-wise results observed were largely in harmony with this overall result. Observing the practitioner perception on the significance of different risk sources to susceptibility of their supply chains across all industries except for Chemical and Pharmaceuticals, Environmental risk sources had been recognised as the most significant while Organisation risk sources as the least significant. This observation is a clear indication that supply chain practitioners in Sri Lanka are confident about internal organisational uncertainties that are mostly under their own preview while being particularly sceptical over environmental uncertainties over which they have next to nothing control. Therefore, it appears there is a clear relationship between perceived seriousness of uncertainties and the level of control the respondents have over those uncertainties. Considering the industry-wise supply chain vulnerability, relatively high vulnerability results for Beverage, Food and Tobacco industry and Textile industry could be attributed to the common traits these industries share such as seasonality of products, cross border supply chains, outsourcing, etc.

Overall supply chain resilience in Sri Lanka had been recognised as being moderate. When the industry-wise resilience scores were compared, all except for Beverage, Food and Tobacco sector, had resulted in scores comparable to overall moderate level resilience. Beverage, Food and Tobacco industry had displayed a fairly stronger level of resilience to the Sri Lankan average. One reason for this stronger result could be due to the sizeable representation of that industry by large multinational companies which are rich in resources both financially and process-wise. As such, they could be in a much stronger position to build redundancies and flexibilities to their supply chains making them more resilient as advocated by [7], [30] and [34]. Further, Beverage, Food and Tobacco sector mostly use standard raw materials in their processes, making their operations more flexible. This could be another reason for high resilience results generated for that industry. Examining individual attributes of supply chain resilience, both Anticipation and Resistance attributes had generated better than moderate results, once again indicating that Sri Lankan supply chains are proactive in the supply chain resilience front as well. However, Response \& Recovery attribute was noticed to be lagging behind the other two attributes. This observation once again could be attributed to lack of resourcefulness of the Sri Lankan organisation in general to recover from supply chain disturbances.

All calculated regression coefficients for supply chain vulnerability, SCRM maturity and supply chain resilience demonstrated a positive relationship. However, the regression coefficients for both H1 (Supply chain vulnerability positively influences SCRM process maturity) and $\mathrm{H} 3$ (Supply chain vulnerability positively influences supply chain resilience) could not be considered significant to support respective hypotheses. Food, Beverage and Tobacco industry generating significantly poor SCRM process maturity results while generating the highest vulnerability results could be considered the main reason for $\boldsymbol{H} \mathbf{1}$ to be void. Similarly, Textile industry displaying relatively poor supply chain resilience while being relatively highly vulnerable could have impacted the validity of H3. In addition, Logistics and Transportation sector generating significant results for both 
SCRM process maturity and supply chain resilience while being comparatively less vulnerable could have negatively impacted the supporting of both $\mathbf{H 1}$ and H3. Therefore, only the resultant coefficient for SCRM maturity and supply chain resilience could be considered satisfactory evidence of a significant relationship. Consequently, only H2 (SCRM process maturity positively influences supply chain resilience) could be concluded as supported by this research.

The findings of this research provide insights to the local industry on the strengths and weaknesses associated with their SCRM practices. Each industry needs to account for all potential risks in designing their supply chain since a single vulnerability can severely affect smooth operations. This was shown to be true during the recent outbreak of the COVID-19 pandemic and the curfew imposed by the government to reduce the spread of the virus which resulted in severe consequences (both positive and negative) to many manufacturing supply chains in Sri Lanka. Therefore, practitioners need to investigate their SCRM practices through the findings of this research and a maturity model. This must be embellished with their recent experiences to ensure a smooth and seamless supply chain.

\section{Limitations of the Study and Recommendations for Future Research}

The objective of this research was to gain a preliminary understanding of the SCRM landscape as applicable to manufacturing supply chains in Sri Lanka as a whole. The scope of the study attempted to cover a cross section representing the large cluster of manufacturing industries rather than focusing on a particular industry. Despite this approach of considering a wide range of industries serving the objective of this particular study, it also resulted in limiting some of the in-depth analysis and understandings that could have been more industry specific. This could be considered a future research avenue, building on this research. The selected sample for this research comprised of supply chain professionals with middle to senior level industry experience and graduate level educational background. Given this, it was valid to assume that they would have a reasonable understanding of their organisations' SCRM processes. However, it was not possible to evaluate how directly they were involved with the actual SCRM process itself. Therefore, it is possible that the validity and the reliability of the results obtained in this research could have been improved if the samples comprised exclusively of professionals directly involved in the SCRM process through lengthy discussions.

Therefore, a case study-based approach could be recommended for future empirical research in this area, where the researcher could conduct in depth interviews with professionals directly involved in the SCRM process in a specific organisation or an industry sector. Similar casebased research on Sri Lankan supply chains have added value to the local literature and the practice [35-39]. It is the belief of the authors that this study could serve as the base for any such case study research carried out in the future. Furthermore, a more detailed study of supply chain resilience in Sri Lanka to encapsulate supply chain resilience strategies etc. could also be considered for future research relating to this study.

The authors also recommend the consideration of a follow up study on SCRM practices in Sri Lankan manufacturing supply chains since this paper reports on data collected in June 2019. Since then, the global supply chain has faced severe challenges due to the outbreak of the COVID-19 pandemic and many Sri Lankan manufacturers had faced both positive and negative consequences which are bound to have morphed their perception on SCRM practices. These findings may ideally provide insights into how significant disruptions to the manufacturing supply chain tend to change the belief system and practices of the practitioners.

\section{References}

1. Jüttner, U., Peck, H. and Christopher, M., "Supply Chain Risk Management: Outlining an Agenda for Future Research," International Journal of Logistics, pp. 197-210, 2003.

2. Fahimnia, B., Tang, C., S.,Davarzani, H. and Sarkis, J., "Quantitative Models for Managing Supply Chain Risks: A Review," European Journal of Operational Research, pp. 1-15, 2015.

3. Cucchiella, F. and Gastaldi, M., "Risk Management in Supply Chain: A Real Option Approach," Journal of Manufacturing Technology, vol. 17, no. 6, pp. 700-720, 2006. 
4. Thun, J. H. and Hoenig, D., “An Emperical Analysis of Supply Chain Risk Management in the German Automobile Industry," International Journal of Production Economics, pp. 242-249, 2011.

5. Sheffi, Y., "Supply Chain Management Under the Threat of International Terrorism," The International Journal of Logistics Management, vol. 12, no. 2, pp. 1-11, 2001.

6. Hendricks, K. B. and Singhal, V. R., "Association Between Supply Chain Glitches and Operating Performance," Management Science, pp. 695-711, 2005.

7. Sheffi, Y., The Power of Resilience:How the Best Companies Manage the Unexpected, London: MIT Press, 2015.

8. Sodhi, M. S., Son, B. G. and Tang, C. S., "Researchers' Perspectives on Supply Chain Risk Management," Production and Operations Management, vol. 21, no. 1, pp. 1-13, 2011.

9. Abeyruwan, K. A. N. V., "Exploring the Project Risk Management in Construction Supply Chain of Construction Companies in Sri Lanka," 08 February 2015. [Online]. Available: http://dl.lib.mrt.ac.lk/handle/123/10658.

[Accessed 17 April 2019].

10. Kodithuwakku, C. E. and Wickramarachchi, D. N., "Identifying the Risk Dynamics of Supply Chain Operations in Large Scale Apparel Industry in Sri Lanka," International Journal of Innovation, Management and Technology, vol. 6, no. 4, pp. 272-277, 2015.

11. Sandanayake, Y. G., Dissanayake, T. B. and Oduoza, C., "Construction Supply Chain Resilience in Catastrophic Events," in Risk Management Treatise for Engineering Practitioners, London, IntechOpen, 2018, pp. 97-120.

12. March, J. G. and Shapira, Z., "Managerial Perspectives of Risk and Risk Taking," Management Science, pp. 1404-1418, 1987.

13. Louis, M. and Pagell, M., "Categorizing Supply Chain Risks: Review, Integrated Typology and Future Research," in Revisiting Supply Chain Risk, Springer, Cham, 2018, pp. 329-366.

14. Ivanov, D., Tsipoulanidis, A. and Schönberger, J., "Supply Chain Risk Management and Resilience.," in Global Supply Chain and Operations Management., Springer, Cham, 2018.

15. Manuj, I. and Mentzer, J. T., "Global Supply Chain Risk Management strategies," Internationl Journal of Physical Distribution $\mathcal{E}$ Logistics Management, pp. 192-223, 2008.
16. Truong, H. Q. and Hara, Y., "Supply Chain Risk Management: Manufacturing and Serviceoriented Firms," Journal of Manufacturing Technology Management, 2018.

17. Oliveira, U. R., Marins, F. A., Rocha, H. M. and Salomon, V. A. P., "The ISO 31000 Standard in Supply Chain Risk Management," Journal of Cleaner Production, pp. 616-633, 2017.

18. Rao, S. and Goldsby, T. J., "Supply chain risks: A review and typology," The International Journal of Logistics Management, pp. 97-123, 2009.

19. Heckmann, I., Comes, T. and Nickel, S., "A Critical Review of Supply Chain Risk Definition, Measure and Modeling," The International Journal of Management Science, pp. 119-132, 2015.

20. Khan, O. and Burnes, B., "Risk and Supply Chain Management: Creating a Research Agenda," International Journal of Logistics Management, vol. 18, pp. 197-216, 2007.

21. Tummala, R. and Schoenherr, T., "Assessing and Managing Risks Using the Supply Chain Risk Management Process (SCRMP)," Supply Chain Management: An International Journal, pp. 474-483, 2011.

22. Mendes Jr., P.,Leal, J. E. and Thomé, A. M. T., "A Maturity Model for Demand-driven Supply Chains in the Consumer Product Goods Industry," International Journal of Production Economics, pp. 153-165, 2016.

23. Netland, T. H., Alfnes, E. and Fauske, H., "How Mature is Your Supply Chain? - A Supply Chain Maturity Assessment Test," Working Paper, SINTEF, Norway, 2007.

24. Childerhouse, P., Böhme, T., Deakins, E. and Disney, S. M., "Supply Chain Integration: An International Comparison of Maturity," Asia Pasific Journal of Marketing and Logistics, pp. 531-552, 2011

25. Lapide, L., "Sales and Operations Planning Part III: A Diagnostic Model," The Journal of Business Forecasting, pp. 13-16, 2005.

26. Göçer, A., Yumurtaci, I. Ö., Yurt, Ö. and Baltacioglu, T., "A New Framework for Supply Chain Risk Management Through Supply Chain Management Capability," Yönetim Bilimleri Dergisi, vol. 13, no. 26, pp. 151-174, 2015

27. Oliva, F. L., "A Maturity Model for Enterprise Risk Management," International Journal of Production Economies, vol. 173, pp. 66-79, 2016. 
28. Berg, E., Knudsen, D. and Norrman, A., “Assessing Performance of Supply Chain Risk Management Programmes: A Tentative Approach," International Journal of Risk Assessment and Management, vol. 9, no. 3, pp. 288-310, 2008.

29. Supply Chain Risk Leadership Council, "Supply Chain Risk Management Maturty Model," 2017. [Online]. Available: http://www.scrlc.com/. [Accessed 25 May 2019].

30. Sheffi, Y. and Rice Jr., J., "A Supply Chain View of the Resilient Enterprice," MIT Sloan Management Review, pp. 41-48, 2005.

31. Kamalahmadi, M. and Parast, M., "A Review of the Literature on the Principles of Enterprise and Supply Chain Resilience: Major Findings and Directions for Future Research," International Journal of Production Economics, pp. 116-133, 2016.

32. Tang, C. S., "Perspectives in Supply Chain Risk Management," International Journal of Production Economics, pp. 451-488, 2006.

33. Sekaran, U., Research Methods for Business: A Skill Building Approach, New York: John Wliey \& Sons Inc, 2003.

34. Chopra, S. and Sodhi, M. S., "Reducing the Risk of Supply Chain Disruptions," MIT Sloan Management Review, pp. 72-80, 2014.

35. Perera, H. N. and Sugathadasa, P. T. R. S., "Investigating Manufacturing Supply Chain Transformations: A Sri Lankan Context," in International Symposium on Logistics 2014, Ho Chi Minh City, Vietnam, 2014.

36. Perera, H. N. and Sudusinghe, J. I., "Longitudinal Analysis of Supply Chain Transformation Project Management," in Engineering Research Conference (MERCon) 2017, pp. 153-158, 2017.

37. Perera, H. N., Thibbotuwawa A., Rajasooriyar, C. and Sugathadasa, P. T. R. S., "Managing Supply Chain Transformation Projects in the Manufacturing Sector: Case-Based Learnings from Sri Lanka" in Research for Transport \& Logistics Industry (R4TLI) 2016, Colombo, Sri Lanka, 2016.

38. Premathilaka, M. H. C. A., Perera, H. N. and Sugathadasa, P. T. R. S., "Queue Server Efficacy in the Retail Industry: A Behavioral Study", 2019 IEEE International Conference on Industrial Engineering and Engineering Management. Macao SAR, 2019.
39. Balachandra, K., Perera, H. N. and Thibbotuwawa, A., "Human Factor in Forecasting and Behavioral Inventory Decisions: A System Dynamics Perspective", in Freitag, M., Haasis, H-D., Kotzab, H. and Pannek, J. (eds) Lecture Notes in Logistics Cham: Springer International Publishing, pp. 516-526. doi: 10.1007/978-3-030-44783-0. 2020. 